\title{
PREVENTIVE MAINTENANCE WITH IMPERFECT REPAIRS OF A SYSTEM WITH REDUNDANT OBJECTS
}

\section{METODYKA OBSEUGIWANIA PREWENCYJNEGO SYSTEMÓW Z NADMIAREM}

\author{
Józef OKULEWICZ, Tadeusz SALAMONOWICZ \\ Warsaw University of Technology, Faculty of Transport, Warsaw, Poland \\ E-mails: tsa@it.pw.edu.pl
}

\begin{abstract}
An object ability to realise tasks may be restored by repairing only failed components. This is called imperfect repair, as the object is not as good as new after such a repair. Preventive replacement is an example of imperfect repair as well. The advantage of such maintenance is that it enables controlling a reliability level of a system. Sets of objects' components that should be replaced are derived on a basis of statistical diagnosing with use of data about components failures. The acceptable level of a failure risk while executing transportation tasks has been taken as a criterion of choosing elements to be replaced. An algorithm of selecting components for preventive replacement has been developed. It was shown that a level of system reliability could be controlled by changing an order of a quintile function in coordination and a number of redundant objects. A computer simulation model of the system was used to illustrate derived dependencies.
\end{abstract}

Keywords: Preventive maintenance, imperfect repair, statistical diagnosis, redundancy.

Streszczenie. Przedmiotem artykułu jest metodyka obsługiwania prewencyjnego systemów technicznych $\mathrm{z}$ nadmiarem, $\mathrm{z}$ uwzględnieniem możliwych błędnych procesów obsługowych.

Słowa kluczowe: Obsługiwanie prewencyjne, błędy obsługowe, diagnostyka, układy nadmiarowe 


\section{Introduction}

Preventive replacements of objects' components are used to maintain demanded reliability of system of objects. This way of avoiding failures of individual components in a system was presented in some surveys $[6,9,13]$. There are some policies of applying preventive replacements as age replacement, block replacement, imperfect maintenance, corrective maintenance. The latter can be made as perfect repair, minimal repair, imperfect repair or general repair. A component of an object maintained under an age replacement policy is replaced after failure or at a specified operational age. The time required to replace the failed component is often considered negligible and, after replacement, the component is assumed to be "as good as new". Moreover, if repair and replacement times are considered non-negligible, it is possible to construct models to determine the optimal replacement age in order to maximize the component availability [3].

Another case is when a component or system that is maintained under a block replacement policy is replaced at regular time intervals, regardless of age [11]. The block replacement policy is easier to administer than the age replacement policy because only the elapsed time, rather than the operational time, since the last replacement must be monitored,. However, a component that was just replaced after failure may be replaced again as a part of the planned block replacement. It can be shown that the age replacement policy is preferable to the block replacement policy.

Corrective maintenance actions are those actions that are necessary to restore objects to an operational state after failure, and can be categorized as follows: perfect repair, minimal repair, imperfect repair and general repair. In the above categories, repair may be used interchangeably with replacement. The issue is not whether a repair or replacement takes place. Rather, the issue is the relative age of the component after repair or replacement. For example, if a failed component is replaced with a new one, it is considered the same as if the component was repaired to an "as good as new" condition. Perfect repair models assume that after a corrective maintenance action the component is rendered "as good as new." The perfect repair assumption is reasonable if failed components are replaced with new and identical ones or if the repair procedure is thorough enough to negate nearly all of the aging effects. There is an optimal balance between preventive maintenance actions and corrective maintenance actions. In the relevant literature, the term imperfect repair has taken a broad meaning from minimal repair to some mixture of minimal repair and perfect repair [2]. More recently, general repair models have been discussed as the most generally applicable corrective maintenance model that includes perfect repair and minimal repair as special cases [8]. Very rare imperfect repair models have attempted to use component availability as a performance measure instead of cost.

Commonly, the effects of applied maintenance actions are modeled through changes in the failure rate of the component. If replacements are made according to 
a block replacement policy and repair actions bring the state of the component to a value somewhere between that applicable to completely new state and that just prior to failure, this can be interpreted as changes in the chronological age of the object, creating the so called virtual age [5].

Independently of applied preventive policy, the need for high reliability of such a system being used can result in great number of components replaced during preventive actions. As it cannot be considered full restoration of object reliability after maintenance, only components of the object should be replaced. This is a case of imperfect repair of the object.

High reliability is achieved in practice by replacing specific components with new ones. If they are negligible, a criterion of selecting components may depend on level of reliability that is expected.

It is obvious that a range of prophylactic activities depends not only on a reliability level of a system but also on its reliability structure. If there are some redundant objects, they can replace failed objects enabling execution of the planned tasks. A number of redundant objects also depend on the acceptable probability of failure during the task implementation period.

Instead of a method of replacing object at a given rate known from the literature [14], the method of block replacement of sets of chosen components is proposed. This enables achieving demanded level of the set reliability. The method uses statistical characteristics of the objects instead of applying measurable parameters of their components.

\section{A system with redundant objects}

Let us assume that $\mathrm{n}$ objects are essentially required for carrying out the planed tasks. If the entire set consists of $\mathrm{n}$ objects, then an assumption can be made that reliability structure of the system is in series. This imposes high requirements on reliability of each object, which is often not achievable. Then, in order to keep reliability of the set at its required level, redundant objects can be introduced. Adding $\mathrm{k}$ redundant objects allows for considering the system reliability structure as a threshold structure, in this case „n out of $n+k$ ”.

The model of system reliability depends on the way the redundant objects are operating in it. They may play a role of the "cold reserve" (standby system), that is, they passively wait for one of the objects to fail, or the "hot reserve" (parallel system), thus increasing the whole system capacity until one of the objects has failed.

In case of the system ,n out of $n+1$ " with the cold reserve, the reliability function $R_{n+1}(t)$ will be a sum of probabilities for occurrence of the following situations:

- until moment $t$ no object will fail out of $n$ objects in a series system,

- at any moment $\tau<t$ one out of $n$ objects shall fail and will be replaced with a reserve object that will not fail along with the remaining objects at an interval $(\tau, \mathrm{t})$. 
Probabilities for occurrence of the above situations are as follows, respectively:

$$
\begin{gathered}
P_{1}=R^{n}(t), \\
P_{2}=\int_{0}^{t} f_{n}(\tau) R_{n}(\tau, t) d \tau,
\end{gathered}
$$

where:

$$
\begin{aligned}
& R_{n}(\tau, t)=\left[\frac{R(t)}{R(\tau)}\right]^{n-1} R(t-\tau), \\
& f_{n}(\tau)=\frac{d}{d \tau}\left[1-R^{n}(\tau)\right]=n R^{n-1}(\tau) f(\tau)
\end{aligned}
$$

Substituting (2) and (3) for (1) yields

$$
\mathrm{P}_{2}=\mathrm{n} \cdot \mathrm{R}^{\mathrm{n}-1}(\mathrm{t}) \int_{0}^{\mathrm{t}} \mathrm{f}(\tau) \mathrm{R}(\mathrm{t}-\tau) \mathrm{d} \tau
$$

Hence

$$
R_{n+1}(t)=P_{1}+P_{2}=R^{n-1}(t)\left[R(t)+n \int_{0}^{t} f(\tau) R(t-\tau) d \tau\right]
$$

where $R_{n+1}(t)$ is a reliability function of " $n$ out of $n+1$ " system, $R(t)$ is a reliability function of an object, $R_{n}(\tau, t)$ is a probability of a non-failure in the interval $(\tau, t)$ of the set consisting of (n-1) objects aged $\tau$ and one new object, $f(t)$ is a probability density function of an object's failure and $\mathrm{f}_{\mathrm{n}}(\tau)$ is a probability density function of a failure of one out of $\mathrm{n}$ identical objects in a series system.

The following relation and no recurrence formulas are known express probability density function of a failure of the system "n out of $n+1$ " with the cold reserve:

$$
f_{n+1}(t)=n R^{n-1}(t) \int_{0}^{t}\left[f(t-\tau)+(n-1) \frac{f(t)}{R(t)} R(t-\tau)\right] d F(\tau)
$$

In case of the system „n out of $n+2$ ", the analytical description becomes more complex, as there is the second reserve object. This means that in the set, established at the moment $\tau$ and consisting of (n-1) objects aged $\tau$ and one new object, one of the objects may fail and be replaced with the second reserve object before the moment $t$. 
In case of the system „n out of $n+k$ ” of identical objects with the hot reserve, we may use the following relation:

$$
\mathrm{R}_{(\mathrm{n}, \mathrm{n}+\mathrm{k})}=\sum_{\mathrm{i}=\mathrm{n}}^{\mathrm{n}+\mathrm{k}}\left(\begin{array}{c}
\mathrm{n}+\mathrm{k} \\
\mathrm{i}
\end{array}\right) \mathrm{R}^{\mathrm{i}}(1-\mathrm{R})^{\mathrm{n}+\mathrm{k}-\mathrm{i}}
$$

and the recurrence formula:

$$
\mathrm{R}_{(\mathrm{n}, \mathrm{n}+\mathrm{k})}=\mathrm{R} \cdot \mathrm{R}_{(\mathrm{n}-1, \mathrm{n}+\mathrm{k}-1)}+(1-\mathrm{R}) \cdot \mathrm{R}_{(\mathrm{n}, \mathrm{n}+\mathrm{k}-1)}
$$

where $\mathrm{R}$ is reliability of a single object.

Complexity of the analytical description, regardless of simplifying assumptions that have been made (i.e. identical objects, omission of the reliability structure of objects alone), indicates that there is a need for using a computer simulation for issues being considered here.

\section{Preventive replacements with statistical diagnosis}

A method that is known from literature and used for defining a scope and deadlines of preventive replacements is to include the costs of attentive replacements and the costs generated by the occurring failures $[1,12]$. As a result of application of this method, minimum average costs per unit of time related to maintained objects in a proper reliability status are achievable. However, in order to benefit from that effect there is a need to replace individual components at various time intervals, usually uncoordinated with the objects' operations, which may wipe out advantages resulting from the implemented optimization. Therefore, a possibility should be considered to make preventive replacements of selected components of objects at the assumed time intervals. Its scope can be defined on the basis of assessment of reliability of the components and the assumed reliability level of the entire set [7]. The system maintained in such a way preserves its ability to carry out the planned tasks with a given probability.

A series system in case of complex objects can be considered. Thus, a failure appears whenever any component has failed. A repair usually involves a replacement of the component with a brand new one.

However, the replacement of the damaged component with the new one does not result in recovery of such a reliability level as that before occurrence of the failure. This is because the value of the reliability function of the damaged component before the failure was less than 1 , and following the replacement it was equal to 1 . In effect, the condition of the object after the repair is - and must be - slightly better than that before the failure. So, practically there are no possibilities to recover such a status of the object following the repair, as the one right before the failure.

Both the objects and their components are considered when developing the preventive replacements policy. Properties of the components are more predicable 
than those of objects which they are part of. Dynamic determination of a scope of preventive replacements could be based on a statistical assessment of present status of objects' components.

The term is widely used to describe a situation when decision about the system state is taken on the basis of a statistical analysis of data. In this case the statistical analysis gives distribution function of lifetime of the object. On this basis a mean time to failure is calculated. In order to do that, data are required about a distribution of time to failure and its parameters as well as about its operational use so far (since being new or from the moment of its replacement).

The problem is in determining a moment when working object should be replaced to prevent its failure. This decision should be made according to a particular object on the basis of statistical data concerning the whole population of objects. So data from the past - i.e. gathered in a computerized system - should be used to calculate parameters of a distribution function of lifetime of the objects. They concern failures, repairs and replacements of object components. Alternative way is relying upon experts' opinions at the start. Next, the probability distribution function of time to failure for each of these components is determined. Then a procedure of selecting objects to preventive replacement is used. Thus, it could be called as preventive maintenance on the basis of statistical data.

The statistical diagnosis is a maintenance methodology in the area of maintaining objects with non-exponential distributions. It identifies preventive maintenance actions to realize the inherent reliability of equipment at a minimum expenditure of resources. Because of statistical parameters of objects it can be performed at any moment. It could be done either in a constant period of time or during planned service or during running repair. Also the distribution parameters are modified when either repair or replacement of the component has been done.

This way the actual technical condition of the object is not taken into consideration, as that would require for the object to be excluded from its operational use. Having data, reliability characteristics of components, updated working time of individual components, and a period for execution of the task, it is possible to define components that require preventive replacement in order for the project implementation probability not to decline below its assumed value. The procedure statistically predicts failures at part level by calculating the mean residual lifetime to failure (MRL).

Parameters of distribution for all chosen components are kept in the computer system. When time comes for diagnosing the MRL for each of all chosen components is calculated according to the formula:

$$
r(t)=\frac{1}{R(t)} \int_{t}^{\infty} R(x) d x
$$

where $r(t)$ is a mean residual lifetime function, $R(x)$ is a reliability function and $t$ is a time from previous replacement. 
However, the MRL compared to required work period results in that about half of objects would undergo services before failure and the rest would fail without any treatment. Thus, instead of the MRL, it would be better to apply a quantile function of residual lifetime to enlarge the probability of preventive maintenance. This measure directly relates to predicted work period and the reliability of the system. For any moment $t$ the following conditions have to be met:

$$
\mathrm{q}_{\mathrm{p}}(\mathrm{t}) \geq \mathrm{d},
$$

where $d$ is a tasks implementation period and $q_{p}(t)$ is a quantile of residual lifetime function, order $p$.

Function $\mathrm{q}_{\mathrm{p}}(\mathrm{t})$ shall be defined as in [4]:

$$
\mathrm{q}_{\mathrm{p}}(\mathrm{t})=\mathrm{F}_{\mathrm{t}}^{-1}(\mathrm{p})=\inf \left\{\mathrm{x}: \mathrm{F}_{\mathrm{t}}(\mathrm{x}) \geq \mathrm{p}\right\},
$$

where $F_{t}(x)$ is a cumulative distribution function of the residual lifetime, $R_{t}(x)$ is a conditional reliability function, and

$$
1-F_{t}(x)=R_{t}(x)=\frac{R(t+x)}{R(t)}, \quad x, t \geq 0 .
$$

It is also true that:

$$
R\left(t+q_{p}(t)\right)=(1-p) R(t) .
$$

The statistical diagnosing can be applied both to components and to complex objects. In a case of complex object, its reliability structure as well as special procedure of choosing components to replace would be considered, which enables achieving demanded probability of proper work of the object [7], [10]. Probability of a failure during a task period can be determined in both cases, that is, when the replacements either have or have not been made. Additionally, the assessment may refer to the entire set of objects that have been assigned for execution of the tasks. If $k$ objects work as the hot reserve, it is the system " $n$ out of $n+k$ " and the order $p$ represents demanded level of reliability. However, in the case of $\mathrm{k}$ redundant objects as the cold reserve, $\mathrm{n}$ objects present a series system. On the basis of the formula (5) it is possible to calculate a new value for the lower level of demanded reliability, with the formula:

$$
1-\alpha_{k}=\frac{1-p}{(1-R)^{k}\left[\left(\begin{array}{c}
n+k \\
n
\end{array}\right)+\sum_{i=1}^{k}\left(\begin{array}{c}
n+k \\
n+i
\end{array}\right)\left(\frac{R}{1-R}\right)^{i}\right]}
$$

where $\alpha_{k}$ is a probability of failure of one of $n$ objects $\left(\alpha_{0}=p\right), p$ is a acceptable probability of system failure, $\mathrm{R}$ is a reliability of a single object, $\mathrm{n}$ is a number of objects needed for the tasks execution and $\mathrm{k}$ is a number of redundant objects.

Procedural way of pointing out the new order $\alpha_{\mathrm{k}}$ is presented in Figure 1. First, a quantile for the system " $\mathrm{n}$ out of $\mathrm{n}+\mathrm{k}$ " is calculated for the order $\mathrm{p}$. Then the reliability $\mathrm{R}$ of a single object for the same quantile is calculated for the system 
" 1 out of 1 ". With use of these values the order $\alpha_{k}$ can be calculated, which is the order for the structure "n out of n".

a)

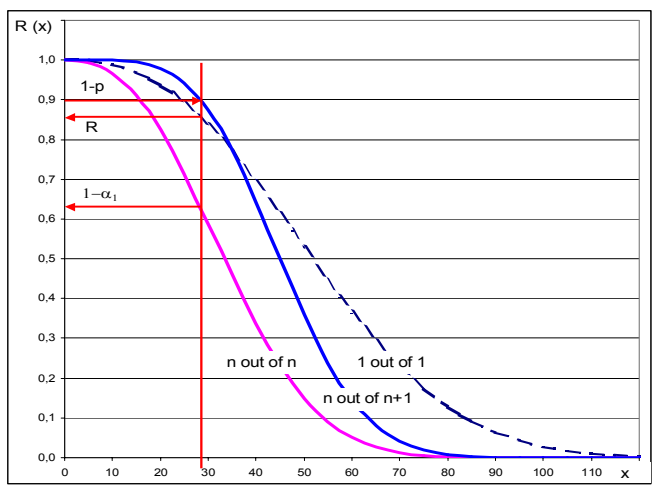

b)

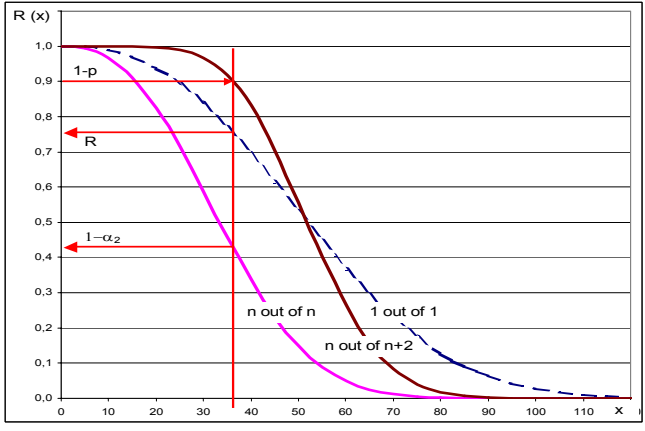

Fig. 1 Graphical interpretation of orders calculation on the basis of structures "n out of $n+k$ ", "n out of $n$ " and "1 out of 1 ": a) "n out of $n+1$ ", b) "n out of $n+2$ "

\section{Imperfect repair}

Majority of theoretical conclusions concerning maintenance are derived from assumption of perfect object restoring. However, such processes with use of models of full renewal are adequate only when an object is replaced with a new one or in a case of a general repair. In the case of corrective repairs made after failing of any object component, a model of minimal repair is often used [1]. This means that the object is to be restored to the condition just before failure. However, it is practically not possible, as object reliability status after repair of its component is better than that before failure. Those are reasons that theoretical models of either perfect or minimal repairs have limited applicability. Real repair restores object reliability to an intermediate value, and it is called an imperfect repair. However, a degree of object restoration by replacing one or more its components can be estimated only after repair. Modeling of the exploitation process with use of the imperfect repairs means defining characteristics of random variable $X_{k}$ concerning time of proper work after $(\mathrm{k}-1)^{\mathrm{th}}$ repair. Object's reliability function after the first repair at moment $t$ is given by the following formula [10]: 


$$
\mathrm{R}_{2}(\mathrm{x})=\left[\mathrm{R}_{1}(\mathrm{x})\right]^{\alpha}\left[\frac{\mathrm{R}_{1}(\mathrm{t}+\mathrm{x})}{\mathrm{R}_{1}(\mathrm{t})}\right]^{1-\alpha}
$$

where $\mathrm{R}_{1}(\mathrm{x}), \mathrm{R}_{2}(\mathrm{x})$ are reliability functions of the object before and after the repair, respectively, $\alpha$ is a degree of the object restoration and $t$ is a moment of the repair.

The formula for the failure rate function relation before and after the repair is as follows:

$$
\lambda_{2}(\mathrm{x})=\alpha \lambda_{1}(\mathrm{x})+(1-\alpha) \lambda_{1}(\mathrm{t}+\mathrm{x}) .
$$

Hence

$$
\alpha=\frac{\lambda_{1}(\mathrm{t}+\mathrm{x})-\lambda_{2}(\mathrm{x})}{\lambda_{1}(\mathrm{t}+\mathrm{x})-\lambda_{1}(\mathrm{x})},
$$

where: $\lambda_{1}(\mathrm{x}), \lambda_{2}(\mathrm{x})$ are failure rate functions before and after the repair, respectively.

The preventive replacements of components of complex objects are made if the value of function (6) - calculated for the objects - is lower than the duration of the scheduled task planned. The appropriate algorithm is presented in Figure 2.

In order to select such a subset of components to be replaced at a given moment, an updated value of the reliability function is calculated, including operational time of each and every one of them. Then a quantile of a given order is calculated for a distribution of the residual lifetime of each component.

The components are put in order according to the growing quantile value. Then subsequent components are assigned for replacement, starting from a component of the lowest quantile value until the quantile of the entire set of objects - calculated by having included the replacement of assigned components with brand new ones is not lower than the duration of the scheduled task. The replacement of components that have been assigned in that way ensures the assumed probability that the object will not fail during implementation of the task.

\section{Simulation experiments}

The above consideration was confirmed with use of a computer simulation. A system " $\mathrm{n}$ out of $\mathrm{n}+\mathrm{k}$ ", for $\mathrm{k}=0,1,2$ was considered as an example. In this model, objects were applied, that were partially replaced at steady intervals of time, according to results of statistical diagnosis. The planned process of replacements was combined with random process of failures and repairs.

The set of $n$ objects was used for execution of tasks in the model. Each object is composed of three groups of different components. The time to failure of a single group was Weibull distribution with a reliability function:

$$
\mathrm{R}(\mathrm{x})=\exp \left[-\left(\frac{\mathrm{x}}{\mathrm{b}}\right)^{\mathrm{a}}\right]
$$




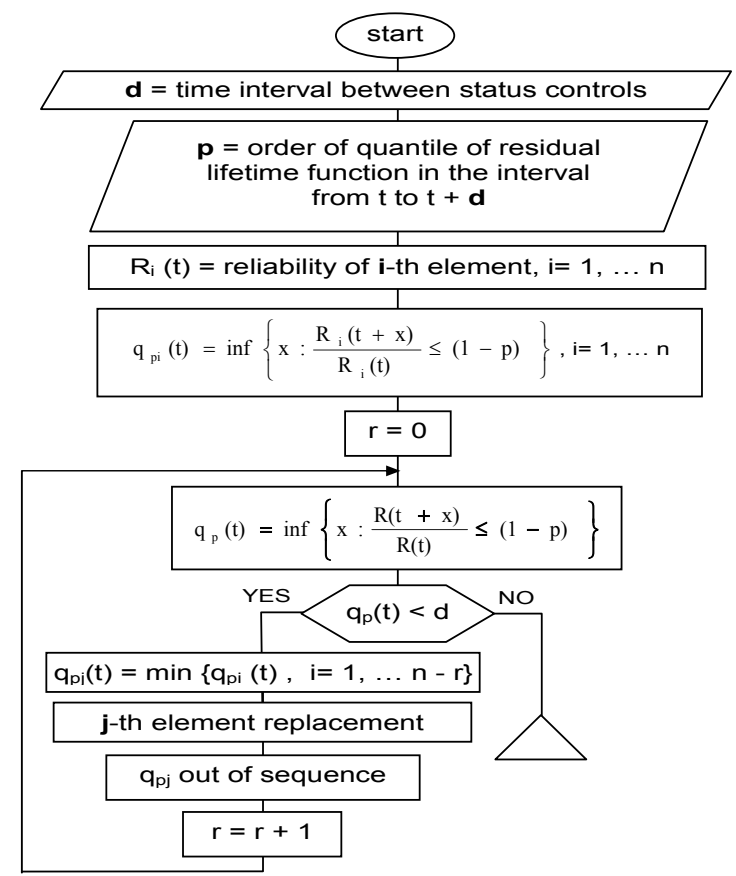

Fig. 2 Algorithm for selecting components for preventive replacement

Parameters of the model were as follows: $\mathrm{n}=50, \mathrm{p}=0.1, \mathrm{~d}=2.5, \mathrm{a}_{1}=2.5, \mathrm{~b}_{1}=65$, $\mathrm{a}_{2}=2.5, \mathrm{~b}_{2}=80, \mathrm{a}_{3}=2.5, \mathrm{~b}_{3}=100$. The acceptable probability of the set unavailability was $\mathrm{p}$. The required reliability was maintained by preventive replacements of objects components. Statistical diagnosing was done at intervals of length d. A graph of the model states is presented in Figure 3.

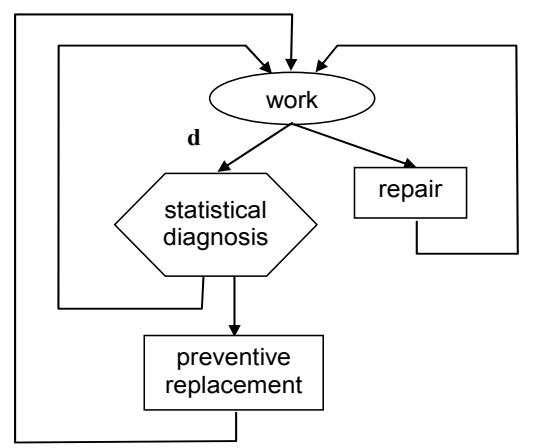

Fig. 3 Graph of model states (work - working of a system, statistical diagnosis - selecting a set of components, preventive replacement - replacement of selected components with new ones, repair - replacement of a failed component with a new one)

The initial state of all objects in the model is "work". After predefined interval d the statistical diagnosis is done. This means that for the set of objects there are chosen these elements of objects which after replacement will cause increasing of 
the probability of this set of objects to the demanded level. This is done according the algorithm in Figure 2.

Then all of these elements are replaced with new ones and objects after such an imperfect repair come back to the initial state. Objects that have not elements to be replaced are going back to the initial state immediately after the statistical diagnosis. For some of elements the real residual time to failure can be less than the interval d. Such an element causes a failure of the object to which it belongs.

Depending on the reliability structure of the system it may cause the failure of this system or not. In the case of $\mathrm{k}$ redundant objects, the $\mathrm{k}+1$ failure will result in the failure of the whole system. After this it undergoes the repair. This means replacing all failed elements with new ones. Such replacements restore the system to a little better state than that before the failure, as some of its elements are new and the rest remain unchanged.

The range of simulation was $\mathrm{T}=1000$, and experiments were repeated 10 times. As a result of simulation, numbers of replacements, failures of objects and unavailability of the whole set were estimated. First of all, the number of failures was estimated for two cases: in the system "n out of n" without any prophylaxis and for the system with statistical diagnosing with $p=0.1$ and $d=2.5$. The mean number of object failures (and the same of the system unavailability) without preventive replacements and with perfect object repair was 1102 . Then this number was increased to 2065 after applying the preventive replacements together with imperfect object repairs. After applying preventive replacements, the mean number of system unavailability was decreased to 42 , according to low probability of failure allowed for that system. But 33568 components have to be preventively replaced in order to sustain the appropriate reliability of objects. Such a great number of replacements in this case were a result of rather low reliability of object components. The empirical reliability of a single object was estimated by the following formula:

$$
\mathrm{R}=1-\frac{\mathrm{N}_{\mathrm{u}} \cdot \mathrm{d}}{\mathrm{T} \cdot(\mathrm{n}+\mathrm{k})}
$$

where $N_{u}$ is a number of object failures, $d$ is a interval of statistical diagnosing, $T$ is a time of simulation, $\mathrm{n}$ is a number of objects and $\mathrm{k}$ is a number of redundant objects.

Using this formula, the reliability of the system was $R_{50}=R^{50}=0.998^{50}=0.900$, so the probability of failure did not exceed the demanded $p=0.1$. Such results show that it is possible to achieve the demanded reliability with significant decrease in the number of random brakes in system work but with a very big number of preventive replacements of components.

Imperfect repairs result in a greater number of system unavailability states than compared to perfect object repairs. This is obvious because repairing only components the object resources are not fully restored, and the object after the repair is not as good as new. Only for exponential distribution numbers of system unavailability with and without perfect repairs are equal to each other. 
The aim of preventive replacements is to decrease number of random object failures by avoiding them with assumed probability, as they break system operation and bring many unpredictable consequences. Adding redundancy to the system also results in enlarging its reliability. According to formula (7) the result of this is analogical to appropriate increasing of the quantile order of the system "n out of n". The modified orders of quantile calculated using formula (7) for systems with $\mathrm{n}+1$ and $\mathrm{n}+2$ objects are as follows: $\alpha_{1}=0.410, \alpha_{2}=0.660$, and interpreted in Figure 4.

Such a result is only valid for a perfect repair after every statistical diagnosing, i.e. each object is replaced with the new one. For complex objects, i.e. composed of some components this condition could be fulfilled when the interval of statistical testing is long enough. However, imperfect repairs - done by replacing selected components of maintained objects - are useful only when the interval between statistical diagnosing is shorter than the initial quantile at $t=0$. After a number of such replacements of objects' components, the system does not consist of new objects. So the probability of tasks fulfilling by a single object cannot be calculated based on reliability function of a new object. Instead of this there should be used systems ,n out of $n+1$ ” and ,n out of $n+2$ " separately on the basis of appropriate experiments from Table 1 . Then in both cases the modified order for system „n out of n" should be calculated with use of formula (7). They are, of course, less than those in the previous case.

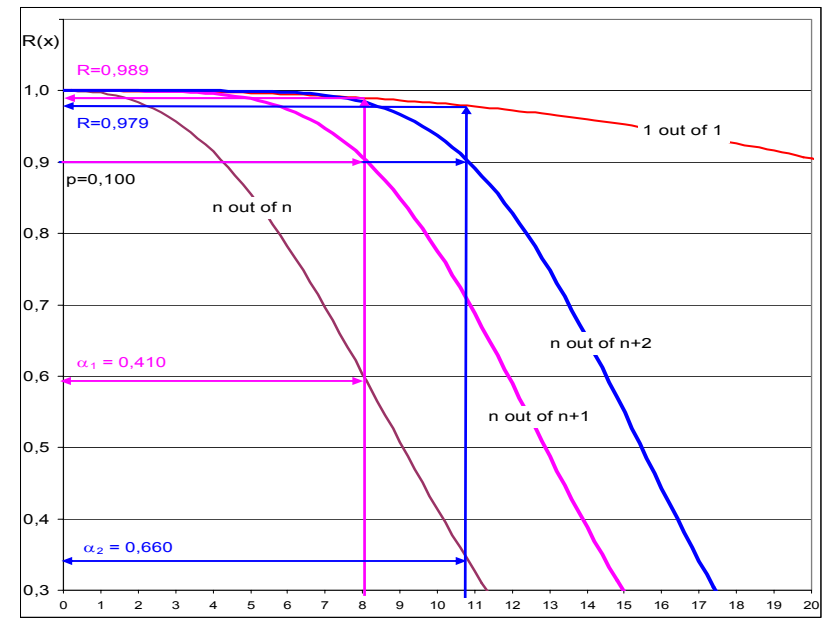

Fig. 4 Graphical interpretation of calculating new quantile orders

Simulation results in Table 1 showed that the numbers of replaced components in systems " $n$ out of $n+1$ " with $p=0.1$ and " $n$ out of $n$ " with $p=\alpha_{1}$ are similar, as well as in systems " $n$ out of $n+2$ " with $p=0.1$ and "n out of $n$ " with $p=\alpha_{2}$ 
Table 1. Simulation experiments results (for $d=2,5$ )

\begin{tabular}{|c|c|c|c|c|}
\hline $\mathrm{p}=0.10$ & \multicolumn{4}{|c|}{$\mathrm{n}$ out of $\mathrm{n}+\mathrm{k}$} \\
\hline $\mathrm{k}$ & 1 & 0 & 2 & 0 \\
\hline$\alpha$ & - & 0.346 & - & 0.482 \\
\hline Number of: & & & & \\
\hline - preventive components replacements & 14405 & 14638 & 10886 & 9807 \\
\hline - group 1 & 7434 & 10213 & 5340 & 6582 \\
\hline - group 2 & 4516 & 2982 & 3435 & 2175 \\
\hline - group 3 & 2455 & 1443 & 2112 & 1050 \\
\hline - system unavailability & 23 & 174 & 16 & 256 \\
\hline - object failures & 154 & 174 & 238 & 256 \\
\hline Reliability of a single object & 0.992 & 0.991 & 0.989 & 0.987 \\
\hline
\end{tabular}

The results of simulations also confirmed a natural supposition, that components of the lowest reliability constitute a dominating group of replaced components. The share of such components in the total number is greater than without statistical diagnosing. These components were recognized and the algorithm assuring the demanded level of the system reliability did such a shifting.

The reliability of a single object according to formula (8) for the system "50 out of 51 " was $\mathrm{R}=0.992$. So the reliability of the system " 50 out of 51 " - according to formula (4) - was $R_{50,51}=0.943$. The reliability of the system " 50 out of 50 " estimated with use of these data was $R_{50,50}=0.647$ and it was appropriate to demanded probability of failure $\alpha_{1}=0,346$. As is shown in Table 1 , the mean numbers of replaced objects in systems "n out of $n$ " with $p=\alpha_{1}$ and "n out of $n+1$ " with $p=0.1$ are similar, as well as in systems "n out of $n$ " with $p=\alpha_{2}$ and "n out of $n+2$ " with the same $p=0.1$.

\section{Conclusion}

The imperfect repairs are a natural way of maintaining objects ability to perform given tasks. They better fit with real situations, since the perfect repair policy is quite unrealistic in case of objects. Preventive replacement of object's components is a kind of imperfect repair as it restores the object capacity partially. This way a considerable reduction in a number of incidental failures of objects, compared to a use without any prophylaxis, is achievable through application of the statistical control. However, maintaining a high reliability of a set of objects is accompanied by a great number of preventive replacements of objects' components. This means that there are many more preventive replacements than random failures of objects because of relatively low reliability of a single object.

Thus in such a situation, it would be easier to achieve the required availability of the system by adding redundant objects that replace the damaged ones than to maintain a high reliability of that system without redundancy. Adding surplus objects and properly matching them with the quantile order applied to the main part of the set of objects could achieve required level of system reliability. So, by 
adding redundant objects, more failures of objects can be accepted as well as a number of preventive replacements is reduced. It would be useful to combine redundancy and preventive replacements based on statistical diagnosing. By those two measures, random failures of the system are significantly reduced in number of replaced components being much lower than those without redundancy.

The hereto-presented method for setting a scope of preventive replacements, based on reliability properties of individual objects being used, allows for matching the parameters of replacements for applied reliability parameters of the objects. Reliability analysis with respect to preventive replacements can also be performed with reference to objects' components being of critical importance to tasks that are executed. This analysis can be carried out for any system of complex objects that will jointly be used for execution of the tasks.

\section{References}

1. Barlow R.E., Proschan F.: Mathematical Theory of Reliability, SIAM Philadelphia, 1996.

2. Brown M., Proschan F.: Imperfect Repair. Journal of Applied Probability, v. 20, p. 851-859, 1983.

3. Cassady C.R., Maillart L.M., Bowden R.O., Smith B.K. Characterization of Optimal Age-Replacement Policies. Proceedings of the Annual Reliability and Maintainability Symposium, p. 170-175, 1998.

4. Joe H., Proschan F.: Percentile residual life functions. Operations Research, v. $32(3)$, p. 668-679, 1983.

5. Kijima M.: Some Results for Repairable Systems with General Repair. Journal of Applied Probability, v. 26, p. 89-102, 1989.

6. McCall J.: Maintenance Policies for Stochastically Failing Equipment: A Survey. Management Science, v. 11 (5), p. 493-524, 1965.

7. Okulewicz J., Salamonowicz T.: Porównanie wybranych strategii odnów profilaktycznych. Materiały XXXIV Zimowej Szkoły Niezawodności, p. 218227, 2006.

8. Pham H., Wang H.: Imperfect Maintenance. European Journal of Operational Research, v. 94, p. 425 - 438, 1996.

9. Pierskalla W., Voelker J.: A Survey of Maintenance Models: The Control and Surveillance of Deteriorating Systems. Naval Research Logistics Quarterly, v. 23, p. 353-388, 1976.

10. Salamonowicz T.: Model niepetnej odnowy przy naprawach wymuszonych i profilaktycznych. Materiały XXXIII Zimowej Szkoły Niezawodności, p. 464 469, 2005 .

11. Shaked M., Zhu H.: Some Results on Block Replacement Policies and Renewal Theory. Journal of Applied Probability, v. 29, p. 932-946, 1992.

12. Smalko Z.: The basic maintenance strategies of machines and equipment. Archives of Transport, v.3, no 3, 1991.

13. Valdez-Flores C., Feldman R.: A Survey of Preventive Maintenance Models for Stochastically Deteriorating Single - Unit Systems. Naval Research Logistics, v. 36, p. 419 - 446, 1989.

14. Wang H.: A survey of maintenance policies of deteriorating systems. European Journal of Operational Research 139, p. 468 - 480, 2002. 